\title{
2006-2655: EMERGING TOPICS FOR INDUSTRIAL ENGINEERING CURRICULUM
}

\section{Luis Rabelo, University of Central Florida}

LUIS RABELO, Ph.D., is an Associate Professor in the Department of Industrial Engineering and Management Systems at the University of Central Florida in Orlando, Florida. He received dual degrees in Electrical and Me-chanical Engineering from the University of Panama and Master degrees from the Florida Institute of Technology and the University of Missouri-Rolla. He received a Ph.D. in Engineering Management from the University of Mis-souri-Rolla in 1990. He also holds dual MS degrees in Aerospace Systems Engineering \& Management from the Massachusetts Institute of Technology.

\section{Ethling Hernandez, University of Central Florida}

Ethling Hernandez is a Master's Degree student of the Engineering Management program in the College of Engineering and Computer Science. She obtained her undergraduate degree in Industrial Engineering in December 2004, from UCF. She is a student member of the Industrial Engineering Society as well as the Society of Hispanic Professional Engineers. Since 2003, Ethling has been a Research Assistant for the IEMS department. Some of her interests are Project Management, Program Development and Quality.

\section{Lesia Crumpton-Young, University of Central Florida}

Lesia Crumpton-Young, Ph.D., is the Chair of the Department of Industrial Engineering and Management Systems in the College of Engineering and Computer Science at the University of Central Florida, in Orlando, Florida. She received her Ph.D. in Industrial Engineering from Texas A\&M University, as well as her Master of Science and Bachelor of Science from Texas A\&M University. Prior to coming to UCF, she was an Associate Dean of Engineering for Research and Outreach at Mississippi State University. Dr. Crumpton-Young's primary research interests are in Human Performance Modeling, Industrial Ergonomics, Ergonomic Design for Special Populations, Occupational Safety and Health, Virtual Reality, Human Reliability, and Information Security. Her teaching areas of specialty are industrial ergonomics, occupational biomechanics, ergonomic design for special populations, safety engineering, work physiology, work design and human factors engineering. Dr. Crumpton-Young is the Primary Investigator (PI) on the Reengineering the Undergraduate IE Curriculum NSF research project.

\section{Hamidreza Eskandari, University of Central Florida}

HAMIDREZA ESKANDARI is a Ph.D. candidate in the Department of Industrial Engineering and Management Systems at the University of Central Florida in Orlando, Florida. He received his Bachelor's degree in Electrical Engineering from the University of Tehran in 1998 and his Master's degree in Socio-Economic Systems Engineering from the Iran University of Science and Technology, Tehran, Iran in 2001. His research interests include Simulation Modeling and Analysis, Multiple Criteria Decision Making, Multiobjective Optimization and Curriculum Development. He is a member of IIE and INFORMS.

\section{Serge Sala-Diakanda, University of Central Florida}

SERGE N. SALA-DIAKANDA is a Ph.D. student in the Department of Industrial Engineering and Management Systems at the University of Central Florida. He holds a B.S in Aerospace Engineering from Embry-Riddle Aero-nautical University, a M.S. in Manufacturing Processes and Systems and a Certificate in Quality Assurance from the University of Central Florida. He has worked as a research assistant with the Center for NASA Simulation Research Group since the fall of 2003. His areas of interest include information fusion, aircraft design and object-oriented simulation of aircraft, and spacecraft development. 
Sandra Furterer, University of Central Florida

Sandra L. Furterer, Ph.D. is the Assistant Department Chair in the Industrial Engineering and Management Systems department in the College of Engineering and Computer Science at the University of Central Florida. Dr. Furterer's research and teaching interests are change management related to application of Lean Enterprise and Six Sigma, as well as engineering education.

\section{Kent Williams, University of Central Florida}

Dr. Kent Williams, Ph.D., is an Associate Professor in the Department of Industrial Engineering and Management Systems in the College of Engineering and Computer Science at the University of Central Florida. He received a Ph.D. in Cognitive Psychology/Human Information Processing from the University of Connecticut, and an M.A. in General Experimental

Psychology/Neuroscience from Connecticut College. His specialties are Simulation and Training Systems Design and Development, Cognitive Science, Cognitive Simulation and Cognitive Modeling, Intelligent Tutoring Systems, Human Computer Interface Design and Evaluation, Human Learning and Memory, among other areas. He is redesigning the instructional strategies using Cognitive Learning Theories for the Reengineering the Undergraduate IE Curriculum NSF research project. 


\title{
Emerging Topics for Industrial Engineering Curriculum
}

\begin{abstract}
The primary purpose of this study was to identify the desired characteristics of an undergraduate Industrial Engineer as an entry-level employee, and to determine the emerging topic areas that should be incorporated into the reengineered curriculum. This research study will help determine the future focus on curriculum development to be more responsive to the needs and requirements of industry.

This paper will explain the process to validate and obtain the different emerging topics. The principal research method employed was a modified three round Delphi study that targeted Industry and Academia. The research findings obtained from the first round of the study are discussed that identify the desired characteristics, and the most important emerging topics to be incorporated into the reengineered curriculum.
\end{abstract}

\section{Introduction}

The Department of Industrial Engineering and Management Systems at the University of Central Florida has received a grant from the National Science Foundation (NSF) to Reengineer the curriculum of Industrial Engineering. One of the first steps is to study and to obtain the different emerging topics to be included in this curriculum.

It is very well known in the $21^{\text {st }}$ Century that the new varied forces of globalization, the development of electronic commerce which is a true manifestation of World Wide Web, the appearance of new methodologies/tools to integrate engineering and business functions, supply chain management and their complex interrelationships are shaping the competitive landscape of business. This new force brings opportunities and makes it necessary to reformulate, streamline, and update Industrial Engineering. These new forces have created the need for emergent topics and modifications to existing ones, which will be covered in this paper. This paper will explain the process to validate and obtain the different emerging topics. We started with surveys including Industry and Academia. Then, we proceeded with a systematic Delphi study.

The organization of the paper is as follows. The objective of the research study is explained in section two. The methodology employed is described in section three, followed by the results and findings of the study in section four. Finally, conclusions and recommendations are given in section five.

\section{Purpose of the Study}

The primary purpose of this study was to identify the desired characteristics of an undergraduate Industrial Engineer as an entry-level employee, and to determine the emerging topic areas that should be incorporated into the reengineered curriculum. This research study will help determine the future focus on curriculum development to be more responsive to the needs and 
requirements of industry, particularly the increasing nontraditional industry sectors such as information Technology (IT) and service, as well as Industrial Engineers' roles in engineering management and leadership. This study will also determine the depth of the emerging topics, how they should be combined and integrated into the curriculum, and how the existing courses should be restructured for new topic inclusion.

\section{Methodology}

The Delphi technique is a systematic procedure that pools the opinions of a diverse group of experts located in different geographical areas whose opinions are important for decision analysis. Through the Delphi technique different responses and views are obtained on the underlying problem resulting in the generation of new ideas, unique suggestions, and eventually gains consensus on the findings among a panel of experts. A conventional Delphi method starts with an open-ended questionnaire and the participants are asked to answer the question(s). A second questionnaire composed of collated information and calculated statistics obtained from the first round questionnaire is sent out asking respondents to revise their opinions about the problem under study. This process continues until the consensus is gained among respondents or the research team determines that they have acquired sufficient data for their study.

Many researchers have used different variations of the Delphi technique to rank and rate the relative importance of the desired attributes and characteristics of university graduates ${ }^{9}$, to identify the competent curriculum contents and topics for undergraduate and graduate education programs ${ }^{5,4,3,6,7}$ and even both ${ }^{8}$. For example, Shah $(2003,2004)$ recently did an extensive research study to discover and describe the competency areas considered most important in the discipline of Engineering Management to update and validate the curriculum for the Master of Science in Engineering Management degree at Eastern Michigan University. In another study, Snoke and Underwood (1999) conducted an Australian national study to examine the generic attributes of graduates of Australian undergraduate degree programs with majors in Information Systems. Wright, Cushman, and Nicholson (2002) investigated the desired attributes of graduates from apparel design programs using Q-methodology. They also examined the disparity of thoughts between the faculty and industry professionals.

Several variations of the Delphi technique are found in the literature. It is reported that it is very difficult for the respondents to rank the questionnaire items when the number of them is quite large ${ }^{10 .}$ For this study, the respondents were asked to rate rather than rank the questionnaire items. A few researchers developed the Delphi technique by sending the second round questionnaire to the new respondents who had not been involved in the first round of the study (for example, see Watson (1989)). This modification will facilitate the group decision-making process by saving a great amount of experts' time and effort, which is probably one of the main drawbacks of Delphi, and by distributing the manpower consumption among the existing experts. On the other hand, this modified Delphi can explore the ideas of the existing experts more thoroughly and gain more information and distinct views.

To reengineer the curriculum, the respondents were asked to 
1. Use a rating scale (Five point Likert scale, in order of increasing importance, where $1=$ very unimportant, 2 = unimportant, $3=$ somewhat unimportant/somewhat important, $4=$ important, $5=$ very important) to rate each characteristic according to its importance for an Industrial Engineer to possess after having completed their undergraduate education

2. Use a rating scale (Five point Likert scale, in order of increasing importance, where $1=$ very unimportant, $2=$ unimportant, $3=$ somewhat unimportant/somewhat important, $4=$ important, $5=$ very important) to rate each characteristic according to its importance for an Industrial Engineer to learn in their undergraduate curriculum.

The population surveyed included faculty from various universities offering an undergraduate degree in Industrial Engineering Program as of May 2004, and industry professionals from different industry sectors including some members of Industrial Advisory Boards of a few Industrial Engineering Departments.

\subsection{Round one}

The first round of the study consisted in distributing a questionnaire with previously identified set of characteristics and emerging topics designed by the research team as an initial question set to approximately 400 potential participants from different universities and industries at the Institute of Industrial Engineers Research Conference (IERC). They were asked to provide an importance rating for the desired characteristics that they would like an undergraduate Industrial Engineering graduate to have, and an importance rating for emerging topics that they believe should be part of an IE undergraduate curriculum. The respondents were asked their rank and their industry sectors. Space was also provided for the respondents to add additional desired characteristics, and emerging topics, or to provide any comments or suggestions at the end of the questionnaire in order to find out the important desired characteristics, and emerging topics that might have been excluded. Out of about 400 questionnaires distributed, 62 completed questionnaires were received resulting in participation rate of $15.5 \%$. Totally, 38 respondents including $22(58 \%)$ from universities, and $16(42 \%)$ from industry provided optional demographic information. Analysis of the collected data for the study consisted of calculating a percentage level of being important or very important for each questionnaire item.

\subsection{Round two}

Round two, currently in process, is the round in which the desired characteristics and emerging topics with quite low importance ratings were eliminated and a few suggested desired characteristics and emerging topics were added to the previous questionnaire. This modified questionnaire with the same format was sent via email with one follow-up to about 300 faculty and a few Industrial Advisory Boards of Industrial Engineering Departments who had not participated in the first questionnaire. A total of 46 completed questionnaires were received including 30 from faculty with a participation rate of about $10 \%$ and 16 from industry professionals, that is, members of Industrial Advisory Boards. The responses from round one and round two were combined together resulting in overall 108 completed surveys, 52 completed surveys from education part across 39 States and 32 completed surveys from industry part across 18 States. Figure 1 shows the faculty professional rank percentages of 52 academic respondents (a), and industry sector percentages of 32 respondents from industry (b). 


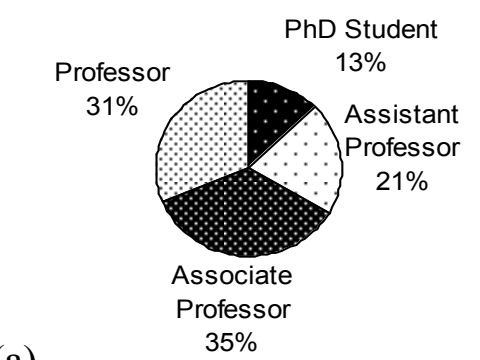

(a)

Figure 1: Faculty rank of the 52 academic respondents (a), and industry sector of the 32 industry respondents (b).

\subsection{Round three}

The third round will determine the final ranking of the 25 most important emerging topics and the 10 most important desired characteristics. These will be derived from the results from a panel of 20 experts including 10 faculty and 10 industry professionals. They will be asked to provide a rank and a weight (1-100) for the important emerging topics and desired characteristics, having referred to the summary of the responses to the recent questionnaire. In this round, obtaining consensus and final ranking on the emerging topics and desired characteristics is the goal.

\section{Findings}

The resultant characteristics and emerging topics that were considered to be very important from round one(overall 62 completed questionnaires) are listed in Table 1 and Table 2, respectively. The desired characteristics and emerging topics are ranked in order of importance, from most to least important, based on the percent of ratings in the important and very important categories across all responses including respondents from education, industry and others.

Table 1: Statistical results on desired characteristics

\begin{tabular}{|c|c|c|c|c|}
\hline \multirow{2}{*}{ Rank } & Desired Characteristics & \multicolumn{3}{|c|}{$\%$ of (Very) Important } \\
\cline { 3 - 5 } & & Education & Industry & Others \\
\hline \multirow{2}{*}{1} & Adaptable problem solving skills & $100 \%$ & $100 \%$ & $100 \%$ \\
\hline \multirow{2}{*}{2} & $\begin{array}{c}\text { Process } \\
\text { evaluation/analyses/assessment }\end{array}$ & $100 \%$ & $94 \%$ & $100 \%$ \\
\hline 3 & Interpersonal skills/presence & $100 \%$ & $94 \%$ & $100 \%$ \\
\hline 4 & Strong quantitative/analytical & $90 \%$ & $100 \%$ & $100 \%$ \\
\hline 5 & abilities & $86 \%$ & $100 \%$ & $95 \%$ \\
\hline 6 & Human dimension of management & $68 \%$ & $93 \%$ & $86 \%$ \\
\hline 7 & Project management & $86 \%$ & $81 \%$ & $76 \%$ \\
\hline 8 & System of systems view & $95 \%$ & $54 \%$ & $80 \%$ \\
\hline 9 & Leadership awareness & $68 \%$ & $94 \%$ & $76 \%$ \\
\hline 10 & Global perspectives & $68 \%$ & $56 \%$ & $61 \%$ \\
\hline 11 & Complexity theory & $33 \%$ & $15 \%$ & $41 \%$ \\
\hline
\end{tabular}


Table 1 shows that of all the desired characteristics polled, the only one that was considered unimportant is complexity theory. Adaptable problem solving is found to be the most important characteristic, followed by process evaluation/analyses/assessment and interpersonal skills/presence, respectively. It is interesting to note that teamwork skills is the one of the most important desired characteristics from the industry perspective and there is a little difference between the education and industry perspectives. One proportion test indicates that with confidence level of $95 \%$ at least $50 \%$ of respondents believe that all desired characteristics, except complexity theory, are important professional attributes for the IE graduates. A significant proportion of respondents (more than $88 \%$ ) believe that the first five characteristics are important. A Chi-square test has provided sufficient evidence to indicate that there is a statistically significant difference between industry and education perspectives in a few desired characteristics. The industry put more emphasis than education on the leadership awareness and human dimension of management. Education put more emphasis than industry on the system of systems.

Table 2: Statistical results on emerging topics

\begin{tabular}{|c|c|c|c|c|}
\hline \multirow{2}{*}{ Rank } & \multirow{2}{*}{ Emerging topics } & \multicolumn{3}{|c|}{$\%$ of (Very) Important } \\
\hline & & Education & Industry & Others \\
\hline 1 & Supply chain tools and techniques & $80 \%$ & $75 \%$ & $100 \%$ \\
\hline 2 & $\begin{array}{c}\text { Performance } \\
\text { Management/Measurement }\end{array}$ & $76 \%$ & $100 \%$ & $83 \%$ \\
\hline 3 & Lean Enterprise & $86 \%$ & $75 \%$ & $90 \%$ \\
\hline 4 & Leadership & $76 \%$ & $94 \%$ & $85 \%$ \\
\hline 5 & Inventory Control & $81 \%$ & $75 \%$ & $90 \%$ \\
\hline 6 & Enterprise Resource Management & $86 \%$ & $73 \%$ & $84 \%$ \\
\hline 7 & Project Management & $81 \%$ & $81 \%$ & $83 \%$ \\
\hline 8 & Ethical Behavior & $75 \%$ & $88 \%$ & $81 \%$ \\
\hline 9 & Team Building and Facilitation & $70 \%$ & $94 \%$ & $75 \%$ \\
\hline 10 & Heuristic Methods in Optimization & $76 \%$ & $70 \%$ & $79 \%$ \\
\hline 11 & Financial Engineering & $65 \%$ & $94 \%$ & $70 \%$ \\
\hline 12 & Organizational Behavior & $53 \%$ & $94 \%$ & $80 \%$ \\
\hline 13 & Six Sigma/Design for Six Sigma & $79 \%$ & $75 \%$ & $68 \%$ \\
\hline 14 & Ergonomics & $70 \%$ & $73 \%$ & $75 \%$ \\
\hline 15 & Benchmarking & $55 \%$ & $94 \%$ & $71 \%$ \\
\hline 16 & $\begin{array}{l}\text { Statistical Methods for Service and } \\
\text { Transaction-based entities }\end{array}$ & $68 \%$ & $86 \%$ & $63 \%$ \\
\hline 17 & Multiple Objective Optimization & $70 \%$ & $67 \%$ & $68 \%$ \\
\hline 18 & Value Engineering & $65 \%$ & $80 \%$ & $60 \%$ \\
\hline 19 & Lean Six Sigma & $63 \%$ & $75 \%$ & $64 \%$ \\
\hline 20 & Customer Relationship Management & $55 \%$ & $88 \%$ & $60 \%$ \\
\hline
\end{tabular}




\begin{tabular}{|c|c|c|c|c|}
\hline 21 & Human/Computer Interface & $65 \%$ & $50 \%$ & $76 \%$ \\
\hline 22 & Design of Complex Systems & $75 \%$ & $62 \%$ & $58 \%$ \\
\hline 23 & Human-Integrated Systems/Usability & $74 \%$ & $57 \%$ & $60 \%$ \\
\hline 24 & Service Enterprise/Systems & $58 \%$ & $64 \%$ & $68 \%$ \\
\hline 25 & Cognitive Engineering & $60 \%$ & $50 \%$ & $63 \%$ \\
\hline 26 & Knowledge Management & $35 \%$ & $82 \%$ & $68 \%$ \\
\hline 27 & New Product Development & $52 \%$ & $43 \%$ & $73 \%$ \\
\hline 28 & Stochastic Programming & $52 \%$ & $56 \%$ & $56 \%$ \\
\hline 29 & E-commerce & $60 \%$ & $31 \%$ & $60 \%$ \\
\hline 30 & Negotiation and Conflict Resolution & $40 \%$ & $75 \%$ & $45 \%$ \\
\hline 31 & Entrepreneurship & $58 \%$ & $44 \%$ & $50 \%$ \\
\hline 32 & $\begin{array}{c}\text { Strategic Management of } \\
\text { Technology }\end{array}$ & $57 \%$ & $47 \%$ & $48 \%$ \\
\hline 33 & Distributed/Parallel Simulation & $59 \%$ & $50 \%$ & $20 \%$ \\
\hline 34 & Socio-Technical Systems & $60 \%$ & $50 \%$ & $33 \%$ \\
\hline 35 & Component-Based Simulation (HLA) & $33 \%$ & $40 \%$ & $69 \%$ \\
\hline 36 & Software Quality Engineering & $45 \%$ & $60 \%$ & $38 \%$ \\
\hline 37 & $\begin{array}{c}\text { Industry Specific Information } \\
\text { Systems }\end{array}$ & $69 \%$ & $36 \%$ & $32 \%$ \\
\hline 38 & Heterogeneous and Global Databases & $57 \%$ & $30 \%$ & $44 \%$ \\
\hline 39 & Virtual Reality & $45 \%$ & $38 \%$ & $47 \%$ \\
\hline 40 & $\begin{array}{l}\text { Radio Frequency Identification } \\
\text { (RFID) }\end{array}$ & $50 \%$ & $56 \%$ & $33 \%$ \\
\hline 41 & Marketing for Engineers & $35 \%$ & $53 \%$ & $30 \%$ \\
\hline 42 & Geographic Information System & $41 \%$ & $27 \%$ & $38 \%$ \\
\hline 43 & Nanotechnology & $33 \%$ & $40 \%$ & $37 \%$ \\
\hline 44 & Global and Public Policies & $30 \%$ & $40 \%$ & $38 \%$ \\
\hline 45 & Security Technologies & $44 \%$ & $25 \%$ & $33 \%$ \\
\hline 46 & Biotechnology & $37 \%$ & $17 \%$ & $47 \%$ \\
\hline 47 & Network Design and Administration & $47 \%$ & $31 \%$ & $26 \%$ \\
\hline 48 & Semantic Web Technologies & $43 \%$ & $0 \%$ & $41 \%$ \\
\hline 49 & Emergency Management & $30 \%$ & $20 \%$ & $41 \%$ \\
\hline 50 & Wireless Systems & $40 \%$ & $8 \%$ & $37 \%$ \\
\hline 51 & Software Agents & $27 \%$ & $27 \%$ & $35 \%$ \\
\hline
\end{tabular}

Table 2 provides additional insight into what industry and academic professionals consider are emerging topics for Industrial Engineering graduates. There are several emergent topics that are considered very important which can be categorized in areas such as:

\section{- Advanced Information Systems}

There are many emerging topics in the field of information systems. Samples of some of these emerging topics are explained as follows: Semantic Web Technologies, Software Agents, Wireless Systems, Heterogeneous and Global Databases and Security Technologies. 


\section{- Supply Chain Management}

A supply chain is a set of inter- and intracompany processes that produce and deliver goods and services to customers.

\section{- Emergency Management and Catastrophic Recovery}

An Emergency management System is a group of comprehensive systems set up by governments, private sector agencies, and individuals to address natural and man made hazards.

\section{- Complex Systems}

Complex systems are characterized by being largely stable, but subject to change. This is an ideal area for most natural systems to operate in. Most natural systems -both biological and man-made - are complex systems. Any Industrial Engineer needs to know how to dominate complexity and create solutions for complex problems.

\section{- Human Factors Engineering}

Understanding cognitive theory, as well as some fundamental aspects of physiology, are critical to ensuring optimum performance of systems involving human entities. Also, designing systems for maximum usability by humans requires an understanding of human information processing as well as human computer interaction.

\section{- Management/Leadership Skills}

A recent study of about 100 IE programs indicates that very few topics on management and leadership are being taught to our undergraduate Industrial Engineers ${ }^{1}$.

It is surprising that nanotechnology and biotechnology, two rapidly growing technologies, were also found at the bottom of the list. Some other topics including virtual reality, geographical information system, and emergency management are not found important as well. One proportion test indicates that with confidence level of $95 \%$ the first 24 topics have been found to be important to be incorporated into the undergrad IE curriculum by more than $50 \%$ of the respondents.

\section{Conclusion}

This paper presents the initial phase of a study to identify the desired characteristics and emerging topic areas that can be used to reengineer the undergraduate Industrial Engineering curriculum at the University of Central Florida. A modified three-round Delphi technique was performed which included the first round where a survey was delivered to approximately 62 faculty and industry professionals across the U.S. All desired characteristics, expect complexity theory, were found to be important. A large number of management and leadership topics together with a few topics on supply chain management and quality engineering were found to be important topics to be incorporated into the reengineered curriculum, whereas surprisingly some new technologies such as information technologies related topics, nanotechnology, and biotechnology were not found to be important as part of an undergraduate Industrial Engineering curriculum. The Chi-square test has revealed that there was a significant difference between the industry and education perspectives in a few desired characteristics and emerging topics as well. 
The results of this study are beneficial for enhancing the undergraduate Industrial Engineering curriculum at the University of Central Florida, and can serve as a model for curriculum development at other universities. This study could be further extended to identify the desired characteristics and the emerging topic areas for graduate Industrial Engineering degrees.

\section{Acknowledgements}

This study is a part of the NSF funded research project entitled "ReEngineering the Undergraduate Industrial Engineering Program”.

\section{References}

1. Fraser, J.M. (2005), "Benchmarking IE programs," Proceedings of the 2005 American Society for Engineering Education Conference, June 12-15, Portland, Oregon.

2. Furterer, S.L., Crumpton-Young, L., Rabelo, L., Williams, K., (2004), "Reengineering the IE Curriculum, a Departmental Reform Strategy," Presented at the IIE Annual Conference, Houston, TX.

3. Gatchell, D.W., Linsenmeier, R.A., Harris, T.R., (2004), "Determination of the Core Undergraduate BME Curriculum- the $1^{\text {st }}$ step in a Delphi Study," Proceedings of the $26^{\text {th }}$ Annual International Conference of the IEEE EMBS, September 1-5, San Francisco, CA.

4. Philips, B. U., Anderson, G.D. and Ridl, K.A. (2003), "Establishing a Women's Health Curriculum Using the Delphi Method," Education for Healthcare, Vol. 16, No. 2, pp. 155-162.

5. Seagle, E. and Iverson, M. (2002), "Characteristics of the Turfgrass Industry in 2020: A Delphi Study with Implications for Agricultural Education Programs," Journal of Southern Agricultural Research, Vol. 52, No. 1, pp. 1-13.

6. Shah, H.A., (2003), "A Delphi Study to Develop Engineering Management Curriculum at Eastern Michigan University," 24th American Society for Engineering Management National Conference, St. Louis, MO, pp. 531-536.

7. Shah, H.A. (2004), "Results of the Eastern Michigan University Delphi Study on Engineering Management Masters' Program Curriculum," 25th American Society for Engineering Management National Conference, Alexandria, VA, pp. 169-177.

8. Simon, L.A., Haygood, J.D., Alkers, C.L., Doerfert, D.L., Davis, C.S., and Bullock, S. (2004), “Master's Level Agricultural Communications Curriculum: A National Delphi Study," National Agricultural Education Research Conference, St. Louis, MO.

9. Snoke, R., and Underwood, A. (1999), "Generic Attributes of IS Graduates: An Australian IS Academic Study," $10^{\text {th }}$ Australian Conference on Information Systems, Victoria University of Wellington, 1-3 December, pp. 817-824.

10. Watson, R. (1989), "Key Issues in Information Systems Management: An Australian Perspective 1988," Australian Computer Journal, Vol. 21, No. 3, pp. 118-129. 
11. Wright, F., and Cushman, L. and Nicholson, A. (2002), "Reconciling Industry and academia: Perspectives on the Apparel Design Curriculum", Education and Training, Vol. 44, No. 3, pp. 122-128.

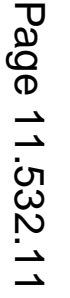

